\title{
Genetic control of copper tolerance in Silene vulgaris
}

\author{
H. SCHAT \& W. M. TEN BOOKUM \\ Department of Ecology and Ecotoxicology, Faculty of Biology, Vrije Universiteit, De Boelelaan 1087, 1081 HV \\ Amsterdam, The Netherlands
}

\begin{abstract}
The genetic control of heavy metal tolerance in higher plants is poorly understood, possibly in part because of several inherent properties of tolerance tests and tolerance measures. In this study we compared different methods of testing for copper tolerance in Silene vulgaris. A new type of multiple concentration test has been used to analyse the genetic control of copper tolerance in this species. Provisional results indicate that the occurrence of any tolerance, relative to a non-tolerant reference population from uncontaminated soil, is governed by a single major gene. The level of tolerance, however, seems to be controlled by a number of modifiers, which are completely hypostatic to the major gene. This model agrees with that proposed for Mimulus guttatus by Macnair (1983).
\end{abstract}

Keywords: copper, tolerance, genetics, rooting test, Silene vulgaris, tolerance index.

\section{Introduction}

Heavy metal tolerance in higher plants is a welldocumented example of small-scale evolution (Antonovics et al., 1971; Ernst, 1976). The genetic control of this phenomenon, however, is imperfectly understood. In a number of genetic studies tolerance was found to be dominant over non-tolerance (Lefèbvre, 1974; Gartside \& McNeilly, 1974a,b). On the other hand, Wilkins (1960), Antonovics (1966) and Urquhart (1971) reported variation in the direction of dominance between crosses. Clear-cut Mendelian segregation in the progeny of crosses between tolerant and non-tolerant plants has been seldomly found to date, which has been interpreted as evidence for polygenic control (Wilkins, 1960; Bröker, 1963; Urquhart, 1971; Gartside \& McNeilly, 1974a,b).

It is possible, however, to dispute the validity of former evidence in favour of polygenic control and variable dominance, as the accurancy of the tolerance index $(T I)$ that has been used in many of the previous genetic studies, i.e.

$T I=\frac{\text { root growth in metal solution }}{\text { root growth in control solution }}$

(cf. Jowett, 1958; Wilkins, 1960) may be limited (Macnair, 1981, 1983). According to Macnair (1983), this index would exhibit an inherently high level of statistical noise. This might relate to the fact that it is a quotient of two variables with presumably differently skewed probability distributions. Moreover, the degree and direction of skewness of the probability distribution of the numerator may be expected to vary with the value of the index, which is in turn dependent on the tolerance level of the plants tested and the metal concentration chosen for testing. Secondly, in spite of its form, $T I$ cannot eliminate all the forms of innate variation in root growth unrelated to tolerance. It is evident that root growth may be affected by genes other than tolerance genes. There is no reason to suppose that these genes would have proportional effects on the two-component parts of $T I$. Humpreys \& Nicholls (1984), for example, observed different dominance relationships for control growth and growth in metal solution in crosses between sensitive and tolerant plants. According to Macnair (1981, 1983), these properties of $T I$ might imply that one is almost bound to find non-Mendelian segregation, irrespective of the number of segregating tolerance genes involved. Another consequence of the use of $T I$ is an imperfect perception of dominance relationships. If the doseresponse curve of the heterozygotes is different from those of the homozygotes, the apparent direction of dominance, as inferred form $T I$-values, will inevitably depend on the metal concentration chosen for testing. Therefore, previously reported variation in the direction of dominance might represent a mere artifact of the testing procedure, rather than a biologically meaningful phenomenon (compare Antonovics, 1968). 
In order to avoid some of the problems associated with TI, Macnair (1983) developed an alternative criterion for tolerance, namely the ability of cuttings to produce roots at a certain fixed test concentration. The latter was chosen in such a way that cuttings of presumed non-tolerant plants (originating from unpolluted sites) consistently failed to root, whereas cuttings of presumed tolerant plants (originating from polluted sites) showed normal rooting. Using this criterion, he obtained convincing evidence from crosses between tolerants and non-tolerants that copper tolerance in Mimulus guttatus is governed by a single major gene. Previously established quantitative variation in the level of tolerance between and within tolerant populations (Macnair, 1976), as well as an apparent degree of heterogeneity between segregating families derived from crosses (Macnair, 1983), were considered to result from a limited number of penetrance or dominance modifiers with small individual effects. The bulk of tolerance was attributed to the major gene itself (Macnair, 1981, 1983). As judged from the doseresponse curves of Mimulus guttatus populations (in Allen \& Sheppard, 1971), however, the test concentration chosen by Macnair (1983), i.e. 0.5 p.p.m. Cu, approximately equals the $E C_{100}$ for root growth (the lowest concentration that inhibits root growth completely) in non-tolerant plants. Therefore, Macnair's method in fact represents a screening for complete non-tolerance, or, in other words, 'tolerance' at the level of the non-tolerant parent. Consequently, Macnair only proved that the very occurrence of any tolerance, relative to a non-tolerant parent, is governed by a single major gene. Due to the qualitative nature of the criterion for tolerance, i.e. growth or no growth at a fixed metal concentration, his method fails to perceive quantitative variation in tolerance, as soon as the level of tolerance exceeds that of the non-tolerant parent. Therefore, Macnair's statements concerning the relative contributions of the major gene and the modifiers must be considered as premature. Furthermore, although Macnair's testing procedure is the only method that has yielded clear-cut results to date (Macnair, 1983), it is not necessarily free from the drawbacks mentioned in connection with the use of $T I$. Firstly, an innate variation in root growth unrelated to tolerance, at least in so far as it might affect $E C_{100}$ levels for root growth, might still produce bias. Secondly, the method does not yield information concerning the precise degree of dominance of tolerance over nontolerance.

In general, any single concentration test will run the risk of an inadequate perception of dominance relationships and quantitative variation in tolerance levels, simply because the relative difference in root growth between any two distinctly tolerant plants will depend on the metal concentration to which they are exposed. The only way to overcome this problem is to use a multiple concentration test. Multiple concentration tests have been used by several investigators (e.g. Davies \& Snaydon, 1973; Craig, 1977; Nicholls \& McNeilly, 1979), although not for the purpose of a genetic analysis. Nicholls \& McNeilly (1979) compared tolerance levels of clones using both $T I$ and a tolerance measure based on a multiple concentration test. Remarkably, they found little agreement between the results obtained with the two measures. Although they did not explicitly reject any of the two measures, they suggested that the results of the multiple concentration test might be more meaningful from an ecological point of view. A multiple concentration test, at least in its usual form, is time-consuming because it involves testing at a more or less extensive series of concentrations. Moreover, if it is used for the purpose of a genetic analysis, it requires cloning of a large number of plants, which is an elaborate procedure, especially in plants without an inherent clonal growth habit. Finally, it is obvious that tolerance measures, based on multiple concentration tests, are not necessarily free from bias due to variation in root growth unrelated to tolerance.

In this study we introduce an alternative type of multiple concentration test, which avoids the need for cloning individual plants. The tolerance measure used in this test is the $E C_{100}$ for root growth, which is established by exposing each individual plant to a test solution in which the metal concentration is raised in time in a stepwise manner. The method is compared with a testing procedure comparable to the one used by Macnair (1983), as well as with a standard multiple concentration test. In addition, a provisional analysis of the genetic control of copper tolerance in Silene vulgaris is presented.

\section{Materials and methods}

All experiments were performed in a climate room $\left(18^{\circ} \mathrm{C}\right.$; 65 per cent $\mathrm{RH}$; light from mercury iodide lamps, $14 \mathrm{~h} /$ day, $235 \mu \mathrm{E} / \mathrm{m}^{2} / \mathrm{s}$ at plant level). Bulk samples of seeds of Silene vulgaris were collected from copper mine waste deposits in Germany, located near Marsberg (Ma), Imsbach (Im) and Harlingerode (Ha). Soil metal contents of these sites are given in Verkleij $e t$ al. (1985). Non-tolerant seed material was collected from a population maintained in the botanical garden of the 'Vrije Universiteit of Amsterdam', The Netherlands (Am). After germination on moist peat soil, a number of seedlings of the populations $\mathrm{Am}, \mathrm{Ma}$ and $\mathrm{Im}$ were planted in $600-\mathrm{ml}$ polyethylene pots with a commercial garden peat soil. They were used to make the 
crosses $\mathrm{Am} \times \mathrm{Ma}$ (10 reciprocal crosses) and $\mathrm{Am} \times \mathrm{Im}$ (10 reciprocal crosses). $\mathrm{F}_{2}$-families of the $\mathrm{Am} \times \mathrm{Ma}$ cross were produced by selfing and crossing random representatives of four random $\mathrm{F}_{1}$-families. Of one of the families produced by selfing an $F_{1}$-plant, 44 random individuals were selfed to produce an $\mathrm{F}_{3}$ generation.

The copper tolerance of seedlings was tested after hydroponic preculture, using 4-litre polyethylene containers provided with a polystyrene floater with 25 perforations in which the seedlings were plugged with nylon wool. The nutrient solution was continuously aerated. Its composition was: $3 \mathrm{~mm} \mathrm{KNO}_{3}, 2 \mathrm{~mm}$ $\mathrm{Ca}\left(\mathrm{NO}_{3}\right)_{2}, 1 \mathrm{~mm} \mathrm{NH} \mathrm{NH}_{2} \mathrm{PO}_{4}, 0.5 \mathrm{~mm} \mathrm{MgSO}_{4}, 50 \mu \mathrm{M}$ $\mathrm{KCl}, 25 \mu \mathrm{M} \mathrm{H}_{3} \mathrm{BO}_{3}, 2 \mu \mathrm{M} \mathrm{ZnSO}_{4}, 2 \mu \mathrm{M} \mathrm{MnSO}_{4}, 0.1 \mu \mathrm{M}$ $\mathrm{CuSO}_{4}, 0.5 \mu \mathrm{M}\left(\mathrm{NH}_{4}\right)_{6} \mathrm{Mo}_{7} \mathrm{O}_{24}, 20 \mu \mathrm{M}$ NaFeEDTA (pH adjusted at 5.5, using $\mathrm{KOH}$ ). After 1 week, during which the $\mathrm{pH}$ was kept between 5.0 and 5.5, the tests were started. For this purpose the nutrient solution was replaced by a test solution of a similar composition, except for the following modifications: (i) NaFeEDTA was omitted, in order to prevent the formation of nontoxic CuEDTA, (ii) the pH buffer MES was added at a $2 \mathrm{~mm}$ concentration, (iii) the $\mathrm{pH}$ was set at 5.0, (iv) $\mathrm{CuSO}_{4}$ was added at the appropriate concentrations. At the start of the tests, the roots were stained black by dipping them in a stirred suspension of finely powdered active charcoal, followed by rinsing in deionized water. This staining method allowed a rapid and highly accurate measurement of root growth. It proved to be non-invasive in pilot experiments. Departures from the intended free copper concentration in the test solution, due to binding of copper ions to cell walls and charcoal particles, were recorded using a cupric electrode (Orion, model 94-01) and appeared to be negligible, except for low copper concentrations (4 $\mu \mathrm{M}$ or less). They were effectively removed by replacing the test solution by a fresh one after an equilibration period of $15 \mathrm{~min}$. Three types of test were applied, first a standard multiple concentration test, in which samples of families or populations were distributed over a geometrical series of copper concentrations. The increase in root length was recorded 2, 4, 6 and 9 days after the start of the test. After each measurement the roots were re-stained and the test solution was replaced by a fresh one. The values of the NEC (the highest concentration which allows uninhibited growth), the $E C_{50}$ (the concentration which reduces growth to 50 per cent of the maximum rate) and the $E C_{100}$ (the lowest concentration which completely inhibits growth) were estimated by regressing root growth on the logarithm of the copper concentration. In order to obtain good linearity $\left(r^{2}>0.95\right)$, non-toxic concentrations and concentrations which arrested root growth completely in a fraction of the family or population tested were excluded from the calculation of the regression line. Secondly, families and populations were tested by exposing each individual plant to an arithmetic series of copper concentrations. The period of exposure to each concentration was 2 days. The roots were stained at the start of the test and prior to each transfer to a higher concentration. At each transfer the plants were qualitatively screened for root growth. Plants that had not grown during the preceding period of exposure were counted and removed. Based on the number of plants removed at each step, frequency distributions of individuals over $E C_{100}$-classes were established for families and populations. Thirdly, families derived from the cross $\mathrm{Am} \times \mathrm{Ma}$ were exposed to $8 \mu \mathrm{M} \mathrm{Cu}$ for 3 days. Then the roots were stained and again exposed to a fresh $8 \mu \mathrm{M} \mathrm{Cu}$ solution. After 2 days the fraction of plants that showed no growth at all during the last 2 days of the test was established. This fraction, multiplied by a factor 2 , was taken as a measure of the fraction of completely non-tolerant plants, because in 50 per cent (44-58 per cent in four replicate tests with 50 plants each) of the non-tolerant population Am the root growth appeared to be completely arrested after 3 days of exposure to $8 \mu \mathrm{M} \mathrm{Cu}$.

\section{Results}

\section{Copper tolerance of populations and $F_{1}$-families of crosses: a comparison of different tests}

The mean root growth as a function of the copper concentration, as established in a standard multiple concentration test (each individual exposed to a single concentration), of different populations and $F_{1^{-}}$ families of crosses (different families lumped together because there was no significant heterogeneity between them) is given in Fig. 1. The copper tolerance level of the populations appears to increase in the order $\mathrm{Am}<\mathrm{Ha}<\mathrm{Ma}<\mathrm{Im}$. Remarkably, the populations $\mathrm{Ma}$ and Im exhibit suboptimal growth at the lowest copper concentration, i.e. $0.1 \mu \mathrm{M}$, whereas the populations $\mathrm{Am}$ and $\mathrm{Ha}$ and the crosses do not. The slope of the linear part of the dose-response curve is variable. The crosses exhibit steeper slopes than the populations $(P<0.01)$. Therefore, the apparent direction of dominance of tolerance depends on the measure of tolerance chosen. NEC-values and, to a lesser extent, $E C_{50}$-values indicate partial dominance of tolerance, especially in the cross $\mathrm{Am} \times \mathrm{Ma}$, whereas $E C_{100}$-values indicate nearly complete recessiveness (Figs 1 and 2). The obviously increased copper requirement for maximum growth, as well as the lower maximum growth rate in 


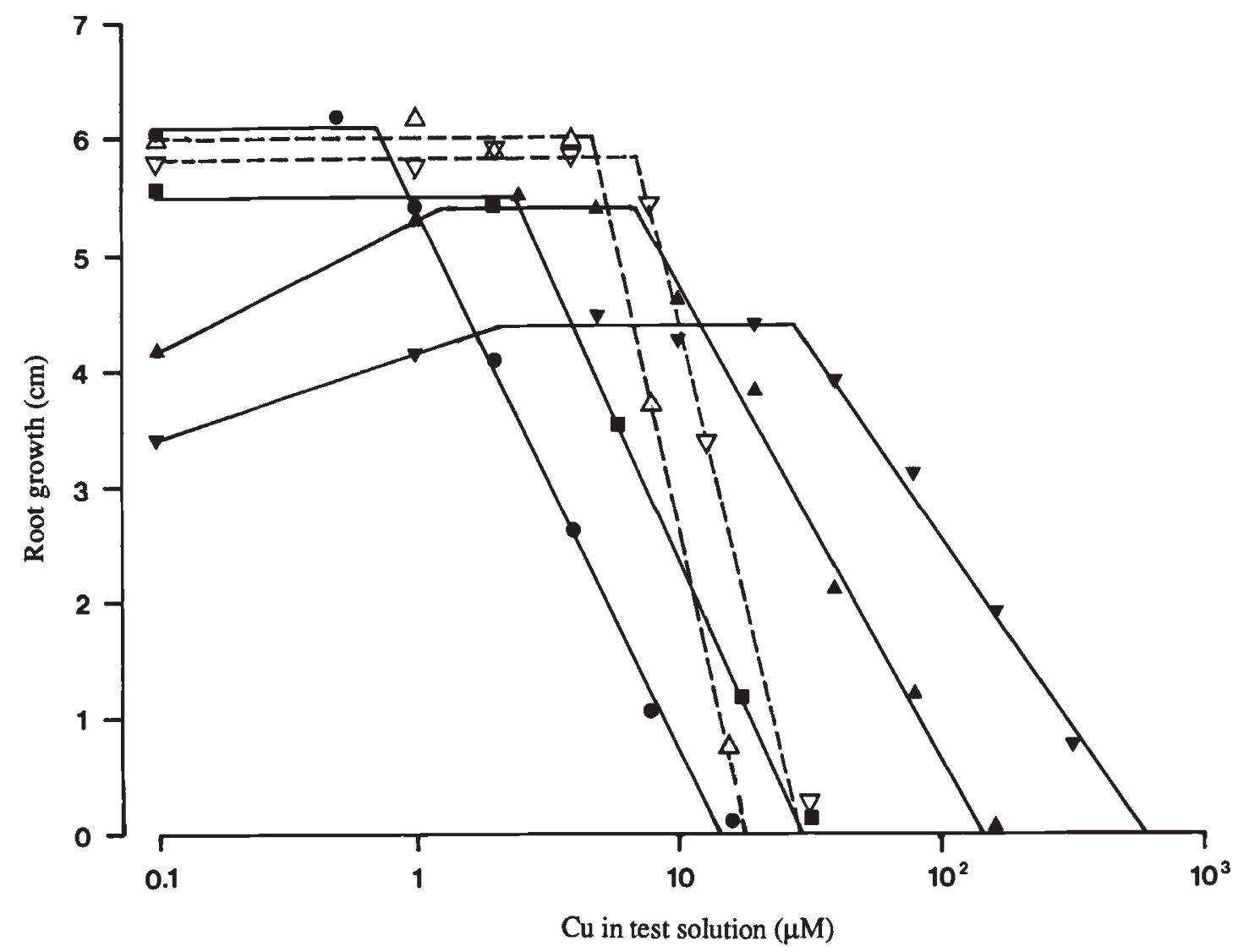

Fig. 1. Increase in root length during a $72 \mathrm{~h}$ exposure to different copper concentrations in a non-tolerant population $(\mathrm{Am}, \bullet)$, three distinctly copper tolerant populations $(\mathrm{Ha}, \boldsymbol{\square} ; \mathrm{Ma}, \boldsymbol{\Delta}$ and $\mathrm{Im}, \boldsymbol{\nabla})$ and the $\mathrm{F}_{1}$ of the crosses $\mathrm{Am} \times \mathrm{Ma}(--\Delta)$ and $A m \times \operatorname{Im}(--\nabla)$.

the populations $\mathrm{Ma}$ and $\mathrm{Im}$ (Fig. 1) also tend to complete recessiveness. At any toxic copper concentration, the root growth rate decreases with time (Fig. 2), whereas at a non-toxic concentration linear growth is maintained for 6 days at least (Fig. 3). In the Am population linear growth is almost restored within 2 days, irrespective of the copper concentration (Figs 2 and 3 ), whereas in the tolerant populations and the crosses the root growth rate continues to drop, although slowly, even after the sixth day of exposure (Fig. 2). Remarkably, the slopes of the dose-response curves remain more or less constant in time (Fig. 2), which implies that each population maintains a more or less constant ratio between its NEC, $E C_{50}$ and $E C_{100}$. On the other hand, in view of the interpopulation differences in the time-dependency of the response to toxic concentrations, it is obvious that the apparent relative differences in tolerance levels between populations and families are, to a certain degree, dependent on the duration of the test.

Some results of the 'sequential exposure test', in which populations and families were tested by exposing each individual to a series of linearly increasing copper concentrations, are given in Table 1. The test obviously provides a sharp distinction between populations and families that proved to be distinctly tolerant in the standard multiple concentration test. Moreover, the sequential test indicates a pronounced and discontinuous variation in tolerance within the $\mathrm{Ha}$ population, which is not apparent in the other populations. The mean $E C_{100}$-values obviously decrease as the magnitude of the concentration intervals decreases. In other words, the mean $E C_{100}$ decreases with the duration of the total period of exposure. This is not surprising, in view of the fact that the effect of any toxic concentration increases, at least initially, with the time of exposure (see above) and that a previous exposure to a lower concentration increases the initial effect of a higher one (Fig. 3).

The results of the single concentration test for complete non-tolerance, in which plants were exposed for 5 days to $8 \mu \mathrm{M} \mathrm{Cu}$ and screened for residual root growth after the third day of exposure, are given in Table 2 . Except for a few individuals of the $F_{1}$ of the cross $\mathrm{Am} \times \mathrm{Ma}$, of which the mean $E C_{100}$ lies very close to that of the non-tolerant population (Fig. 2) and of the 
Fig. 2 Root growth, expressed as a percentage of the maximum rate, regressed on the copper concentration of the test solution, for a non-tolerant population (Am, - - ) two distinctly copper-tolerant populations $(---, \mathrm{Ma}$; $-, \operatorname{Im})$ and the $F_{1}$ of the crosses $\mathrm{Am} \times \mathrm{Ma}$ and $\mathrm{Am} \times \mathrm{Im}$. The four lines given for each population and cross represent, from right to left, the increase in root length throughout day 1 and 2 , day 3 and 4 , day 5 and 6 , and day 7,8 and 9 of the test, respectively.

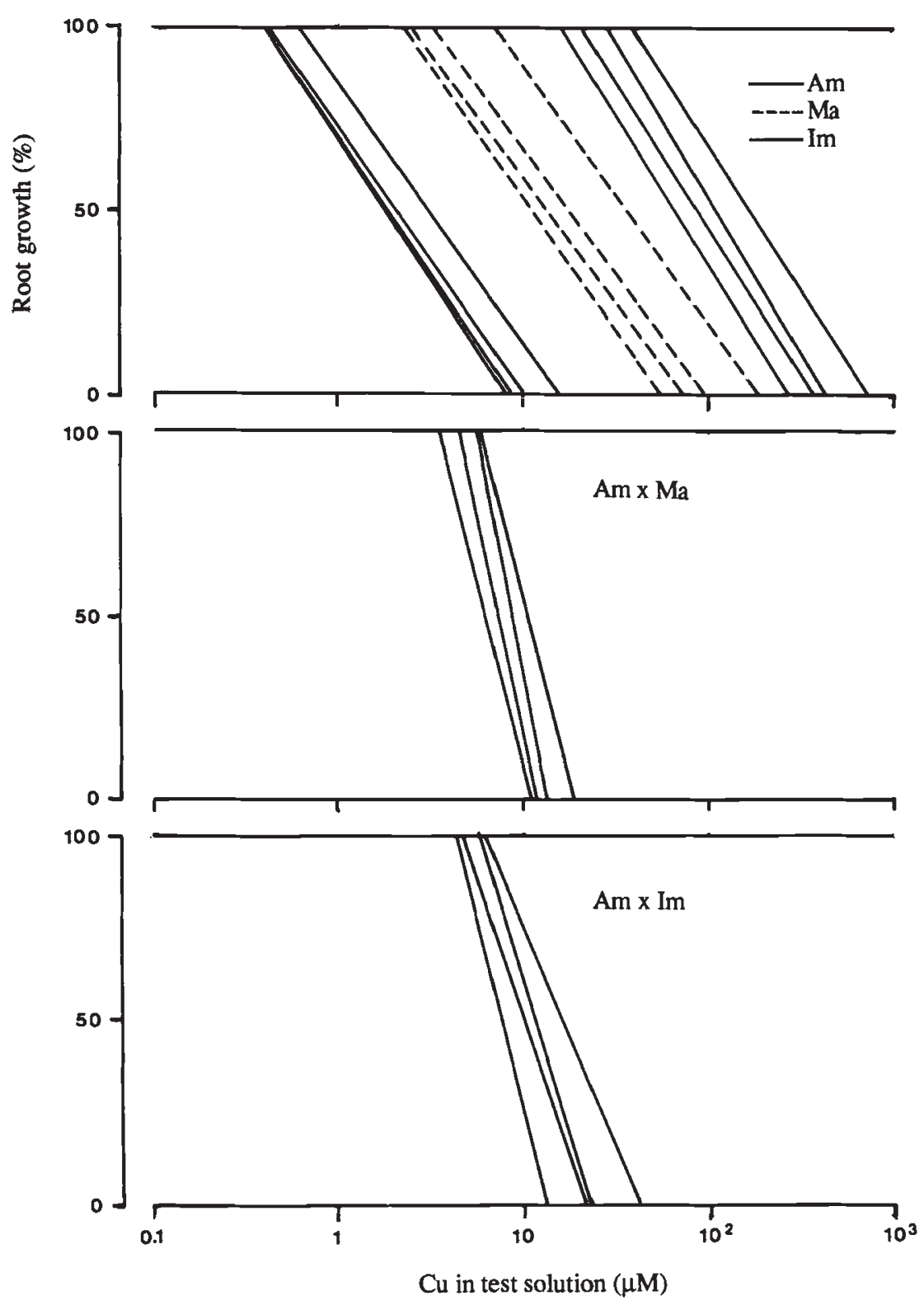

population $\mathrm{Ha}$, which is strongly heterogeneous (see below), the test does not reveal any non-tolerance among the populations and crosses tested.

\section{Genetic control of tolerance in crosses between the populations Amsterdam and Marsberg}

The frequency distribution of the $E C_{100}$, as established in the sequential exposure test performed with $10-\mu \mathrm{M}$ concentration intervals, of the $F_{1}, F_{2}$ and $F_{3}$ of the cross $\mathrm{Am} \times \mathrm{Ma}$ is given in Fig. 4, together with those of the parent populations. The reciprocals of the different $F_{1}$ families always show identical frequency distributions, which proves the absence of any maternal effect (data not shown). The variation in tolerance within the $F_{2}$ and $F_{3}$ is obviously not discontinuous. Remarkably, the modal class of the $F_{2}$ and $F_{3}$, i.e. the $10-20 \mu \mathrm{M}$ class, is the same as that of the non-tolerant population. If it is assumed that all the plants in the $0-10 \mu \mathrm{M}$ class are completely non-tolerant and that 16 per cent of the non-tolerants among the $\mathrm{F}_{2}$ and $\mathrm{F}_{3}$ is to be found within the $0-10 \mu \mathrm{M}$ class, just as in the case of the non-tolerant parent population (Table 1), then the observed frequencies in this class agree very well with the expectations based on a monogenic model (Table 3). Apart from the $\mathrm{F}_{2}$-family given in Fig. 4, another six $\mathrm{F}_{2}$ families of $\mathrm{Am} \times \mathrm{Ma}$ crosses, produced by crossing or selfing $F_{1}$ plants from different parents, have been subjected to the $8 \mu \mathrm{M}$ single-concentration test (100 plants per family). The number of plants without residual 


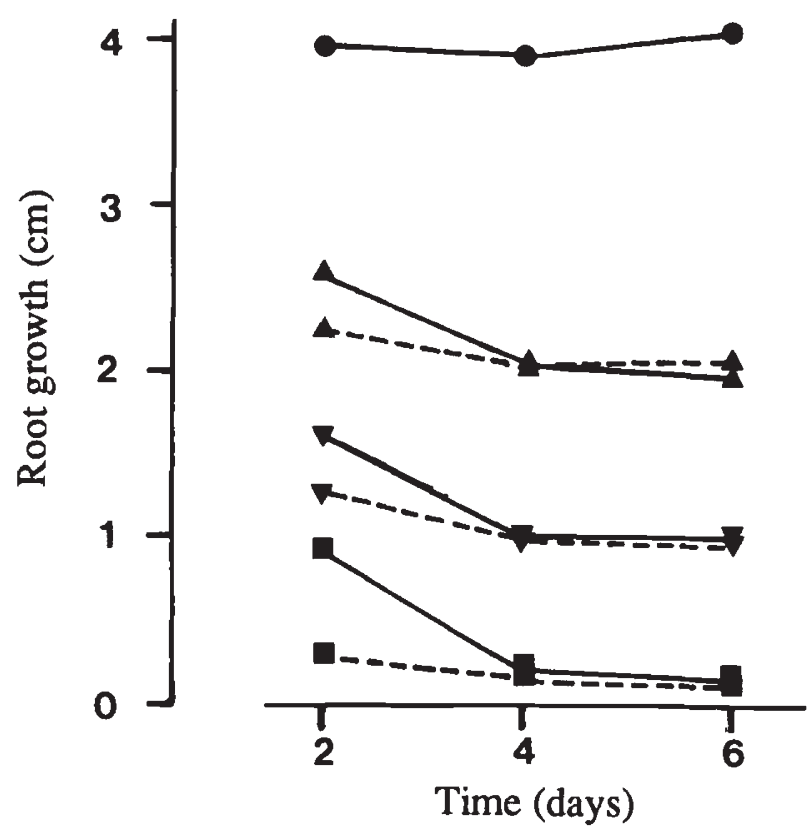

Fig. 3 Root growth of a non-tolerant population (Am) throughout a 6-day exposure to different copper concentrations $(\bullet) 0.1,(\boldsymbol{\Delta}) 2.0,(\boldsymbol{\nabla}) 4.0$ and $(\bullet) 8.0 \mu \mathrm{M} \mathrm{Cu}$. The values at $t=2, t=4$ and $t=6$ represent the root growth throughout day 1 and 2, day 3 and 4 , and day 5 and 6 after the start of the treatment, respectively, both for unpretreated plants $(-)$ and plants that had been treated for 2 days, prior to the test, with half of the copper concentration to which they were exposed at $t=0(---)$. growth after 3 days at $8 \mu \mathrm{M} \mathrm{Cu}$ among these families varies between 8 and 17 (11.2, on the average), which provides additional evidence in favour of a monogenic model for complete non-tolerance. The evidence from the frequency distributions of individual $F_{3}$ families, however, is more ambiguous. The number of families with individuals in the $0-10 \mu \mathrm{M}$ class is lower than the expectation calculated for a monogenic model (Table 4). However, of the 44 families tested 13 do not contain any individual with an $E C_{100}$ higher than $20 \mu \mathrm{M}$. If it is assumed that these families are entirely non-tolerant, then the number of 13 agrees very well with the expectation of 11 for a monogenic model (Table 4). There is a remarkable heterogeneity among the latter families: eight of them do not contain any individual with an $E C_{100}$ lower than $10 \mu \mathrm{M}$, whereas the remaining five exhibit over-representation of such individuals, relative to the non-tolerant parent population. A further analysis of the $\mathrm{F}_{3}$, using the single concentration test for nontolerance, provides comparable results. The total number of plants among a total of 40 families tested, which do not exhibit any residual root growth after 3 days at $8 \mu \mathrm{M} \mathrm{Cu}$, agrees very well with the expectation based on a monogenic model (Table 4). The number of families without non-tolerants, however, is somewhat lower, although insignificantly, than the expectations based on a monogenic model (Table 5). Out of the group of 13 families, which appeared to be devoid of

Table 1 Relative frequencies of individuals (\%) in $E C_{100}$ classes for the effect of copper on root growth, as established in sequential exposure tests performed with different concentration series, for the populations $\mathrm{Am}, \mathrm{Ma}, \mathrm{Im}, \mathrm{Ha}$ and the $\mathrm{F}_{1}$ of the crosses Am $\times$ Ma and Am $\times$ Im

\begin{tabular}{|c|c|c|c|c|c|c|c|c|c|}
\hline \multicolumn{10}{|c|}{$E C_{100}$ class $(\mu \mathrm{M} \mathrm{Cu})$} \\
\hline Concentration & $0-3$ & $3-6$ & $6-9$ & $9-12$ & $12-15$ & $15-18$ & $18-21$ & $21-24$ & $>24$ \\
\hline Am & 0 & 0 & 71 & 29 & 0 & 0 & 0 & 0 & 0 \\
\hline $\mathrm{Am} \times \mathrm{Ma}$ & 0 & 0 & 0 & 3 & 93 & 4 & 0 & 0 & 0 \\
\hline $\mathrm{Am} \times \operatorname{Im}$ & 0 & 0 & 0 & 0 & 40 & 57 & 3 & 0 & 0 \\
\hline \multicolumn{10}{|c|}{$E C_{100}$ class $(\mu \mathrm{M} \mathrm{Cu})$} \\
\hline Concentration & $0-4$ & $4-8$ & $8-12$ & $12-16$ & $16-20$ & $20-24$ & $24-28$ & $28-32$ & $>32$ \\
\hline $\mathrm{Am}$ & 0 & 0 & 100 & 0 & 0 & 0 & 0 & 0 & 0 \\
\hline $\mathrm{Ha}$ & 0 & 0 & 1 & 20 & 0 & 36 & 37 & 0 & 6 \\
\hline \multicolumn{10}{|c|}{$E C_{100} \operatorname{class}(\mu \mathrm{M} \mathrm{Cu})$} \\
\hline Concentration & $0-10$ & $10-20$ & $20-30$ & $30-40$ & $40-50$ & $50-60$ & $60-70$ & $70-80$ & $>80$ \\
\hline Am & 16 & 84 & 0 & 0 & 0 & 0 & 0 & 0 & 0 \\
\hline $\mathrm{Am} \times \mathrm{Ma}$ & 0 & 39 & 60 & 1 & 0 & 0 & 0 & 0 & 0 \\
\hline $\mathrm{Am} \times \operatorname{Im}$ & 0 & 0 & 65 & 34 & 1 & 0 & 0 & 0 & 0 \\
\hline $\mathrm{Ma}$ & 0 & 0 & 0 & 0 & 20 & 32 & 28 & 20 & 0 \\
\hline \multicolumn{10}{|c|}{$E C_{100}$ class $\left(\mu_{\mathrm{M}} \mathrm{Cu}\right)$} \\
\hline Concentration & $0-50$ & $50-100$ & $100-150$ & $150-200$ & $200-250$ & $250-300$ & $300-350$ & $350-400$ & $>400$ \\
\hline Am & 100 & 0 & 0 & 0 & 0 & 0 & 0 & 0 & 0 \\
\hline Ma & 0 & 100 & 0 & 0 & 0 & 0 & 0 & 0 & 0 \\
\hline $\operatorname{Im}$ & 0 & 0 & 0 & 0 & 10 & 55 & 35 & 0 & 0 \\
\hline
\end{tabular}


Table 2 Frequency of individuals among the populations $\mathrm{Am}, \mathrm{Ha}, \mathrm{Ma}, \mathrm{Im}$ and the $\mathrm{F}_{1}$ of the crosses $\mathrm{Am} \times \mathrm{Ma}$ and $\mathrm{Am} \times \mathrm{Im}$, of which the root growth is completely arrested by 3 days of exposure to $8 \mu \mathrm{M} \mathrm{Cu}$

\begin{tabular}{lll}
\hline Population/crosses & Number of plants tested & $\begin{array}{l}\text { Number of plants with } \\
E C_{100}(3 \text { days })<8 \mu \mathrm{M}\end{array}$ \\
\hline $\mathrm{Am}$ & 200 & 99 \\
$\mathrm{Ha}$ & 75 & 1 \\
$\mathrm{Ma}$ & 50 & 0 \\
$\mathrm{Im}$ & 50 & 0 \\
$\mathrm{~F}_{1} \mathrm{Am} \times \mathrm{Ma}^{*}$ & 50 & 1 \\
$\mathrm{~F}_{1} \mathrm{Am} \times \mathrm{Im}^{*}$ & 50 & 0 \\
\hline
\end{tabular}

*A mixture of 10 different families.
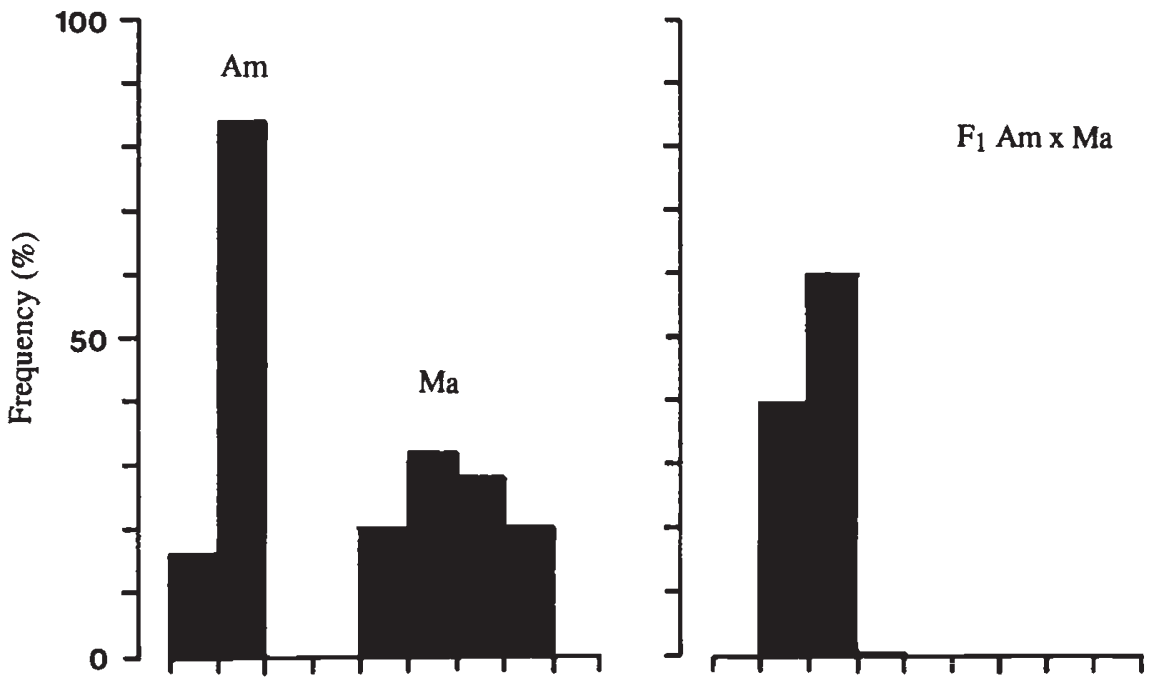

Fig.4 Frequency distribution of $E C_{100}$ values for the effect of copper on root growth, as established in a sequential exposure test using a concentration series of $10,20,30,40 \ldots \mu \mathrm{M} \mathrm{Cu}$, for the parent population $\mathrm{Am}(n=200)$ and $\mathrm{Ma}(n=150)$ and the $\mathrm{F}_{1}($ a total of 20 families with 25 plants each), $\mathrm{F}_{2}(1$ family with $n=478$ ) and $\mathrm{F}_{3}$ (a total of 44 families with 25 plants each) of the
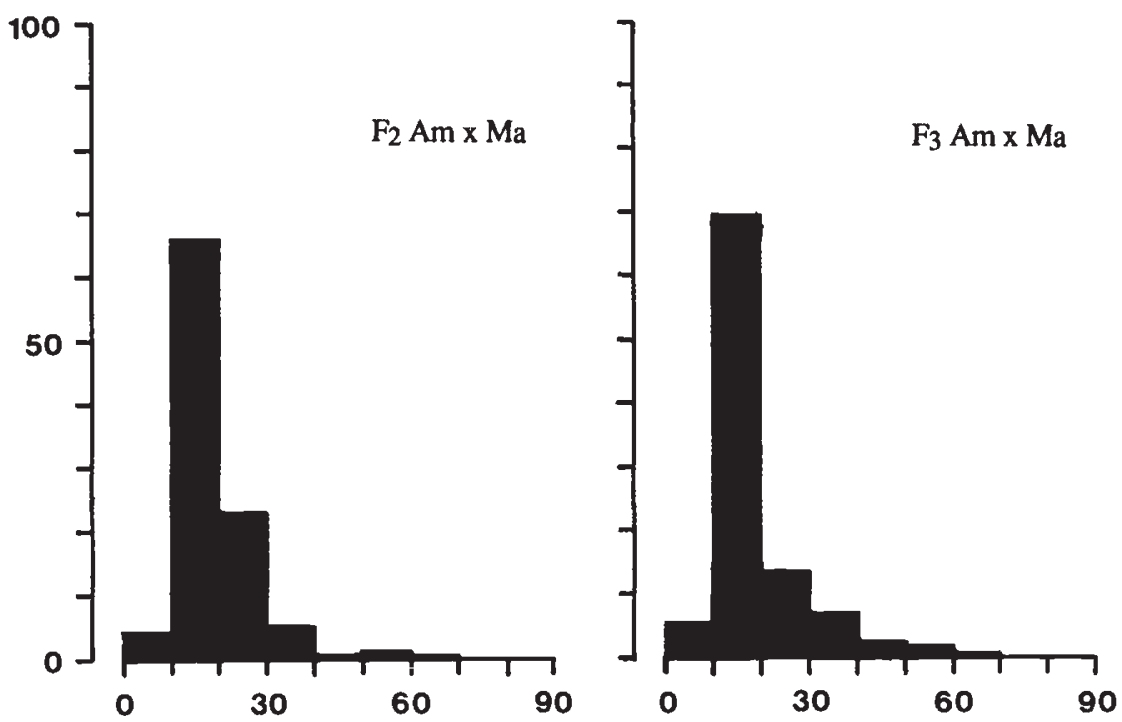
cross $\mathrm{Am} \times \mathrm{Ma}$. 
Table 3 Frequencies of individuals in the $0-10 \mu \mathrm{M}$ class of the distribution of $E C_{100}$ values for the effect of copper on root growth, which have been found among the $F_{2}$ and $F_{3}$ of the cross $\mathrm{Am} \times \mathrm{Ma}$, together with the expected frequencies calculated for different numbers of independently segregating genes $(g)$

\begin{tabular}{|c|c|c|c|c|}
\hline$g$ & $\begin{array}{l}\text { Observed } \\
\text { number }\end{array}$ & $\begin{array}{l}\text { Expected } \\
\text { number }\end{array}$ & $\chi^{2}$ & \\
\hline \multicolumn{5}{|c|}{ Number of plants in $\mathrm{F}_{2}{ }^{*}$ with $E C_{100}<10 \mu \mathrm{M}$} \\
\hline 1 & 18 & 19 & 0.01 & ns \\
\hline 2 & & 5 & 9.59 & $* *$ \\
\hline 3 & & 1 & 9.59 & $* *$ \\
\hline \multicolumn{5}{|c|}{ Number of plants in $\mathrm{F}_{3} \dagger$ with $E C_{100}<10 \mu \mathrm{M}$} \\
\hline 1 & 59 & 66 & 0.35 & ns \\
\hline 2 & & 25 & 34.38 & $* * *$ \\
\hline 3 & & 9 & 61.14 & $* * *$ \\
\hline
\end{tabular}

* A single family produced by selfing a random $\mathrm{F}_{1}$ plant. $\uparrow$ A total of 44 families ( 25 plants tested per family), produced by selfing random representatives of the $F_{2}$ family. ns $=$ not significant; ${ }^{*} P<0.05,{ }^{* *} P<0.01 ;^{* * *} P<0.001$. Expected frequencies lower than 5 have been set at 5 for the calculation of significance levels.

Table 4 Frequency of $F_{3}$ families with at least one individual (out of 25) with an $E C_{100}$ lower than $10 \mu \mathrm{M} \mathrm{Cu}$, and of $F_{3}$ families without individuals with an $E C_{100}$ higher than $20 \mu \mathrm{M}$ $\mathrm{Cu}$. The corresponding expected frequencies have been calculated for different numbers of independently segregating genes $(g)$. Further legends as in Table 2

\begin{tabular}{|c|c|c|c|c|}
\hline$g$ & $\begin{array}{l}\text { Observed } \\
\text { number }\end{array}$ & $\begin{array}{l}\text { Expected } \\
\text { number }\end{array}$ & $\chi^{2}$ & \\
\hline \multicolumn{5}{|c|}{ Number of families in $\mathrm{F}_{3}$ containing plants with $E C_{100}$} \\
\hline 1 & 14 & 25 & 10.16 & $* *$ \\
\hline 2 & & 12 & 1.87 & NS \\
\hline 3 & & 5 & 8.77 & $* *$ \\
\hline \multicolumn{5}{|c|}{ Number of families in $\mathrm{F}_{3}$ without plants with $E C_{100}>20 \mu \mathrm{M}$} \\
\hline 1 & 13 & 11 & 0.13 & NS \\
\hline 2 & & 3 & 9.45 & $* *$ \\
\hline 3 & & 1 & 9.45 & ** \\
\hline
\end{tabular}

Expected frequencies lower than 5 have been set at 5 for the calculation of significance levels.

individuals with an $E C_{100}$ higher than $20 \mu \mathrm{M}$ in the sequential test, 12 have been tested in the single concentration test. All of them, except one, contain individuals for which the root growth stops within 3 days during exposure to $8 \mu \mathrm{M}$ copper. Just like the sequential test, however, this group of families is clearly heterogeneous, the number of plants without residual growth varying between 4 and 21 (out of 25). Of the 31 families, which appeared to contain at least one indivi-
Table 5 Frequency of individuals among the total of $F_{3}$ families of which the root growth is completely arrested by 3 days of exposure at $8 \mu \mathrm{M} \mathrm{Cu}$, and of $\mathrm{F}_{3}$ families which contain such individuals. Further legends as in Table 2

\begin{tabular}{|c|c|c|c|c|}
\hline$g$ & $\begin{array}{l}\text { Observed } \\
\text { number }\end{array}$ & $\begin{array}{l}\text { Expected } \\
\text { number }\end{array}$ & \multicolumn{2}{|l|}{$\chi^{2}$} \\
\hline \multicolumn{5}{|c|}{ Number of plants in $\mathrm{F}_{3}$ with $E C_{100(3 \text { days })}<8 \mu \mathrm{M}$} \\
\hline 1 & 180 & 187 & 0.30 & NS \\
\hline 2 & & 70 & 133.53 & $* * *$ \\
\hline 3 & & 26 & 414.27 & *** \\
\hline \multicolumn{5}{|c|}{$\begin{array}{l}\text { Number of } \mathrm{F}_{3} \text { families containing plants with } E C_{100(3 \text { days })} \\
\quad<8 \mu \mathrm{M}\end{array}$} \\
\hline 1 & 26 & 30 & 1.52 & NS \\
\hline 2 & & 18 & 5.67 & $*$ \\
\hline 3 & & 9 & 31.08 & $* * *$ \\
\hline
\end{tabular}

dual with an $E C_{100}$ above $20 \mu \mathrm{M}$ in the sequential test, 28 have been tested in the single concentration test. Fourteen of them contain individuals without residual growth after 3 days, in a frequency of 1-6 (out of 25). Except for one of them, these 14 families have the majority of individuals in the $10-20 \mu \mathrm{M}$ class in the sequential test. Of the other 14 families only seven have the majority of individuals in the $10-20 \mu \mathrm{M}$ class, whereas the other seven have the majority in higher $E C_{100}$ classes.

In contrast to the very occurrence of tolerance, the level of tolerance seems to be under polygenic control. As judged from the fraction of individuals in the $F_{2}$ and $\mathrm{F}_{3}$, which have an $E C_{100}$ higher than $40 \mu \mathrm{M}$ (i.e. the minimum level in the tolerant parent population), 'full tolerance' (i.e. tolerance at the level of the tolerant parent) seems to be governed by three independently segregating genes (Table 6). Apart from the $F_{2}$ family given in Fig. 4 and Table 6, another six $F_{2}$ families of Am $\times$ Ma crosses have been subjected to the sequential test with $10 \mu \mathrm{M}$ concentration intervals ( 50 plants per family). The number of 'fully tolerant' plants among these families varies between 0 and 4 (1.3, on the average), which tends to confirm the latter hypothesis.

\section{Discussion}

The present study clearly demonstrates some of the merits and restrictions of the different tests and tolerance measures applied in this and other genetic studies. The main problem of a single concentration test is the choice of the test concentration. It is evident that a complete genetic analysis requires a quantitative tolerance measure with a sufficient degree of resolution throughout the entire range of variation in tolerance, which is present among the organisms to be tested. If such a measure is inferred from a single concentration 
Table 6 Frequency of individuals with an $E C_{100}$ for root growth higher than $40 \mu \mathrm{M} \mathrm{Cu}$ among the $\mathrm{F}_{2}$ and $\mathrm{F}_{3}$, and of $\mathrm{F}_{3}$ families, which contain such individuals. Further legends as in Table 2

\begin{tabular}{|c|c|c|c|c|}
\hline$g$ & $\begin{array}{l}\text { Observed } \\
\text { number }\end{array}$ & $\begin{array}{l}\text { Expected } \\
\text { number }\end{array}$ & $\chi^{2}$ & \\
\hline \multicolumn{5}{|c|}{ Number of plants in $F_{2}$ with $E C_{100}>40 \mu \mathrm{M}$} \\
\hline 1 & 6 & 120 & 225.01 & $* * *$ \\
\hline 2 & & 30 & 29.93 & $* *$ \\
\hline 3 & & 7 & 0.02 & NS \\
\hline 4 & & 2 & 0.19 & NS \\
\hline \multicolumn{5}{|c|}{ Number of plants in $\mathrm{F}_{3}$ with $E C_{100}>40 \mu \mathrm{M}$} \\
\hline 1 & 55 & 413 & 654.82 & $* * *$ \\
\hline 2 & & 155 & 96.23 & $* * *$ \\
\hline 3 & & 58 & 0.06 & NS \\
\hline 4 & & 22 & 35.78 & $* * *$ \\
\hline \multirow{2}{*}{\multicolumn{5}{|c|}{ Number of $\mathrm{F}_{3}$ families containing plants with $E C_{100}>40$}} \\
\hline & & & & \\
\hline 1 & 9 & 33 & 55.21 & *** \\
\hline 2 & & 23 & 17.45 & $* * *$ \\
\hline 3 & & 13 & 0.79 & NS \\
\hline 4 & & 5 & 2.34 & NS \\
\hline \multicolumn{5}{|c|}{$\begin{array}{l}\text { Number of } \mathrm{F}_{3} \text { families containing only plants with } E C_{100} \\
>40 \mu \mathrm{M}\end{array}$} \\
\hline 1 & 1 & 11 & 15.53 & *** \\
\hline 2 & & 3 & $\mathrm{NC}$ & \\
\hline 3 & & 1 & NC & \\
\hline 4 & & 0 & $\mathrm{NC}$ & \\
\hline
\end{tabular}

Expectations lower than 5 have been set at 5 for the calculation of significance levels.

$\mathrm{NC}=$ not calculated.

test, then a concentration should be chosen which is toxic to all the genotypes but which allows at least some growth of the most sensitive one. In some cases such a concentration does not exist (e.g. Fig. 2). Even in cases where it does exist, it may be doubtful whether the sensitivity of the index will be sufficiently high throughout the entire range of variation in tolerance present.

The type of single concentration test applied by Macnair (1983), and in this study, implies a basically qualitative criterion for tolerance, which has at least the advantage of a rapid and simple screening procedure. It is easy to conceive, however, that this type of test will only produce interpretable results, if the test concentration is chosen at such a level that the test effectively identifies one of the extreme genotypes (e.g. the completely non-tolerant homozygote). The chance that this requirement can be met is expected to increase as the difference between the extreme genotype and that with the most nearby tolerance level becomes larger. If the difference is small, which may be expected in the case of polygenic control, then the range of suitable test concentrations will be narrow, especially if innate variation in root growth unrelated to tolerance is present (see below). In the case of Mimulus guttatus, there is apparently a concentration which effectively identifies nearly 100 per cent of the non-tolerant homozygotes (Macnair, 1983). In this study, however, we have been forced to apply a concentration at which only 50 per cent of the non-tolerants could be recognized as such because higher concentrations appeared to produce an imperfect discrimination between the non-tolerant homozygotes and the heterozygotes $(\mathrm{H}$. Schat and W. M. Ten Bookum, unpublished observations). The reason for this difference might be that the degree of dominance of tolerance over non-tolerance is lower in Silene cucubalus than in Mimulus guttatus (see Allen \& Sheppard, 1971). Evidently, a test which identifies only a fraction of the completely non-tolerant homozygotes can still be suitable for a genetic analysis. Its accuracy, however will decrease if this fraction becomes too low. This can be demonstrated by comparing the results of the single concentration test with those of the sequential exposure test. In the form which has been applied to the analysis of the Am $\times$ Ma cross, the sequential test has been assumed to identify only 16 per cent of the completely non-tolerant genotypes, whereas the single concentration test has been assumed to identify 50 per cent of them. With respect to the number of identified completely non-tolerant homozygotes among the total of $\mathrm{F}_{3}$ families tested, the results of both tests show an almost equal perfect agreement with the expectations based on the monogenic model (Tables 4 and 5). However, with respect to the number of $F_{3}$ families, which include non-tolerants, the tests provide conflicting results. Whereas the single concentration test still indicates monogenic inheritance, the sequential test indicates digenic inheritance (Tables 4 and 5). It is not unreasonable to explain this apparent contradiction in terms of a differential sensitivity to innate variation in root growth unrelated to tolerance. For example, in this study we calculated our expected frequencies of families which contain non-tolerants by treating the number of identifiable non-tolerants per family as a Poisson-distributed variable, at least for families in which the frequency of identifiable non-tolerants was expected to be low. It is obvious that any variation in $E C_{100}$, which is unrelated to tolerance, would raise the relative frequency of the zero class of the probability distribution of the number of identifiable non-tolerants per family above that of a Poisson distribution with the same mean. This causes more serious discrepancies between observed and expected frequencies, as the number of identifiable non-tolerants per family decreases. On the other hand, the number of identi- 
fiable non-tolerants among the total of $F_{3}$ families will be unaffected by a variation unrelated to tolerance, provided that the total number of $F_{3}$ families tested is sufficiently high. The above does not mean, however, that the sequential test would be inferior to the single concentration test, generally speaking. It is obvious that it must be possible to choose the first concentration of the series at such a level that it provides a more effective identification of the non-tolerant homozygotes. In fact, the sequential test is nothing more than a sequence of single concentration tests of the type applied by Macnair (1983). The main advantage of the sequential test over the Macnair-test is that it provides information concerning the quantitative variation in tolerance among the tolerant genotypes. An obvious drawback of the sequential test is that it produces an overestimation of lower tolerance levels relative to the higher ones. For example, if non-tolerants and tolerants are tested on the same concentration series (Table 1), the relative difference between the mean $E C_{100}$ levels is much smaller than in a standard multiple concentration test (Fig. 1). This is a consequence of the fact that the $E C_{100}$ decreases with the time of exposure (Fig. 2) and that a previous exposure to a lower concentration accelerates the response to a higher one (Fig. 3). It is remarkable that if distinctly tolerant populations are tested on different concentration series, in such a way that the mean $E C_{100}$ is reached after a similar total period of exposure, the relative differences in the mean $E C_{100}$ levels are approximately the same as in the multiple concentration test (compare Fig. 2 and Table 1). Such a distortion of the tolerance scale might hinder an accurate perception of the real magnitude of relative quantitative differences between tolerance levels and of the precise dominance relationships. However, the latter restrictions will also apply to single concentration tests, in general.

An important aspect of any test is the degree of reproducibility of the results. The tests applied to this study, especially the single concentration test for complete non-tolerance, are fairly sensitive to small changes in climatic conditions. If they are, however, performed under constant conditions, the results are highly reproducible, at least in the case of testing for copper tolerance. In the case of testing for cadmium or zinc tolerance, the results have a much lower degree of reproducibility (H. Schat \& W. M. Ten Bookum, unpublished observations). The reason for this might be that root growth responds much faster to copper than to cadmium or zinc or any other metal, apart from mercury and silver (H. Schat \& W. M. Ten Bookum, unpublished observations), probably because the primary target of copper ions is the plasmalemma of the cells of the root apex itself (De Vos et al., 1989). A major part of the long-term effect of copper on root growth is already apparent within a few days (Figs 2 and 3). The response to cadmium and zinc, on the other hand, is much slower. For example, the concentration of cadmium that is required to stop root growth completely within 2 days is about 20 times as high as the lowest concentration that will eventually kill the plant (in the case of copper, these concentrations differ by a factor 2 only). Moreover, even among cloned material, the variation in the rate of response to toxic concentrations is much higher in the case of cadmium than in the case of copper (M. A. De Knecht, personal communication).

The results of the genetic analysis of copper tolerance in the $\mathrm{Am} \times \mathrm{Ma}$ cross are very compatible with monogenic inheritance of tolerance, at least in so far tolerance is defined as any level of tolerance which exceeds that of the non-tolerant parent. The level of tolerance, on the other hand, is clearly under polygenic control, which probably implies that it is in part controlled by one or a few (probably 2) modifier genes, which are hypostatic to a major gene that governs the very occurrence of any tolerance at all. So far, this agrees well with Macnair's model of the inheritance of copper tolerance in Mimulus guttatus (Macnair, 1983). Our results, however, do not support Macnair's idea that the major gene itself would account for 'the bulk of tolerance' and that the modifiers would have only small effects. If this holds true for Silene then a much greater fraction of the $F_{2}$ and $F_{3}$ should exhibit tolerance levels approaching those of the tolerant parent. On the contrary, our $E C_{100}$ frequency distributions seem to suggest that a major part of the potential tolerance is controlled by the modifiers. In view of the lack of precise information concerning the quantitative variation in tolerance amoung tolerant Mimulus guttatus, which is a consequence of Macnair's method of testing, it is possible to maintain that the latter might also hold true for Mimulus guttatus.

\section{References}

ALLEN, W. R. AND SHEPPARD, P. M. 1971. Copper tolerance in some Californian populations of the monkey flower Mimulus guttatus. Proc. R. Soc. B., 177, 177-196.

ANTONOVICS, J. 1966. The genetics and evolution of differences between closely adjacent plant populations with special reference to heavy metal tolerance. Ph.D. Thesis, University of Wales.

ANTONOVICS, J. 1968. Evolution in closely adjacent plant populations. V. Evolution of self-fertility. Heredity, 23, 219-238.

ANTONOVICS, J., BRADSHAW, A. D. AND TURNER, R. G. 1971. Heavy metal tolerance in plants. Adv. Ecol. Res. 7, 1-85.

BROKER, w. 1963. Genetisch-Physiologische Untersuchungen 
über die Zinkverträglichkeit von Silene inflata. Sm. Flora, 153, 122-156.

GRAIG, G. C. 1977. A method of measuring heavy metal tolerance in grasses. Trans. Rhod. Sci. Assoc., 58, 9-16.

DAVIES, M. S. AND SNAYDON, R. W. 1973. Physiological differences among populations of Anthoxanthum ordoratum L. collected from the Park Grass Experiment. Rothamsted. II. Response to aluminium. J. Appl. Ecol., 10, 47-55.

DE Vos, C. H. R., SCHAT, H., voous, R. AND ERNST, W. H. O. 1979. Copper-induced damage to the permeability barrier in roots of Silene vulgaris. J. Plant Physiol., 135, 164-169.

ERNST, W. H. O. 1976. Physiological and biochemical aspects of metal tolerance. In: Mansfield, T. A. (ed) The Effects of Air Pollutants in Plants, Cambridge University Press, Cambridge, pp. 115-133.

GARTSIDE, D. W. AND MCNEILLY, T. 1974a. Genetic studies in heavy metal tolerant plants. I. Genetics of zinc tolerance in Anthoxanthum odoratum. Heredity, 32, 287-299.

GARTSIDE, P. W. AND MCNEILLY, T. 1974b. Genetic studies in heavy metal tolerant plants. II. Zinc tolerance in Agrostis tenuis. Heredity, 33, 303-308.

HUMPHREYS, M. O. AND NICHOLLS, M. K. 1984. Relationships between tolerance to heavy metals in Agrostis capillaris L. (A. tenuis Sibth.) New Phytol., 98, 177-190.

JOWETT, D. 1958. Populations of Agrostis ssp. tolerant of heavy metals. Nature, 182, 816-817.
LEFÈBVRE, C. 1974. Note sure la génétique de la tolerance au zinc chez Armeria maritima (Mill.) Willd. Bull. Soc. $R$. Bot. Belg. 107, 217-222.

MACNAIR, M. R. 1976. The genetics of copper tolerance in Mimulus guttatus (Scrophulariaceae). PhD. Thesis, University of Liverpool.

MACNAIR, M. R. 1981. Tolerance of higher plants to toxic materials. In: Bishops, J. M. and Cook, L. M. (eds) Genetic Consequences of Man-made Change, Academic Press, London, pp. 177-208.

MACNAIR, M. R. 1983. The genetic control of copper tolerance in the yellow monkey flower, Mimulus guttatus. Heredity, 50, 283-293.

NICHOLLS, M. K. AND MCNEILLY, T. 1979. Sensitivity of rooting and tolerance to copper in Agrostis tenuis Sibth. New Phytol., 83, 653-664.

URQUHART, C. 1971. Genetics of lead tolerance in Festuca ovina. Heredity, 26, 19-33.

VERKLEI, J. A. C., BAST-CRAMER, W. B. AND LEVERING, H. 1985. Effects of heavy metal stress on the genetic structure of populations of Silene cucubaluls. In: Haeck, J. and Woldendorp, J. W. (eds) Structure and Functioning of Plant Populations. Noord-Holland, Amsterdam, pp. 355-365.

wILKINS, D. A. 1960 . The measurement and genetical analysis of lead tolerance in Festuca ovina. Rep. Scot. Plant Breed. Sta., pp. 85-98. 